\title{
Use and outcome of online health information services: a study among Scottish population
}

\author{
Jenny Harbour ${ }^{1}$ \\ and \\ Gobinda G. Chowdhury \\ Department of Computer and Information Sciences \\ University of Strathclyde \\ Glasgow G1 1XH \\ Gobinda.chowdhury@cis.strath.ac.uk
}

\begin{abstract}
Purpose: Reports on a research designed to find out how people in Scotland access and use online health information.

Design/methodology/approach: Based on a survey of two sets of population in Glasgow - a group of 64 users from the general public and a group of 24 post graduate students from a university in Glasgow.
\end{abstract}

Findings: Use of the Internet for health information was found to be much lower in Glasgow than in the previous UK studies particularly those using online surveys. Noted that people located online health resources primarily by searching and browsing. Healthy eating, exercise and alternative medicine were the most commonly sought topics. Approximately half the survey participants felt online health information influenced their treatment.

Originality/value: The study incorporates both Internet users and non-users, as well as proficient internet users, and therefore provides a more balanced view.

Keywords: Information access, Health information, Online health information, Information use

Paper type: Research

\section{Introduction}

Demands for access to health information have increased significantly over the last ten or so years (Wallace, 1997). Factors contributing to this increased demand include demographic changes, higher education and literacy levels, increasing competence with new technologies and increasing demands for informed choice (Williams et al., 2002a,2003). Other contributing factors include the increasing popularity of participative health care models, the overwhelming volume of health information available for doctors, limited consultation times, an emphasis on self-care and prevention, and a growing interest in alternative medicine (Cotten and Gupta, 2004)

Since the mid 1990's British government have placed emphasis on providing health information with the belief that providing patients with access to health information will reduce strain on the overburdened NHS services (Dolan et al., 2004; Nicholas, Huntington and Williams, 2003a). The consensus among researchers is that around 70,000 health websites currently exist (Cline and Haynes, 2001; Benigeri and Pluye, 2003; Diaz et al., 2002). In the UK health websites are produced by the government, the NHS, charities, commercial organisations, private individuals, online medical journals, Royal Colleges, pharmaceutical companies and support groups (Wilson, 1999; Garnes and Mills, 2001).

\footnotetext{
${ }^{1}$ Jenny Harbour has recently graduated from the department with an MSc in Information and Library Studies. She can be contacted at: JennyHarbourUK@,Yahoo.co.uk
} 
Sources of health information can be categorised as non-interactive or interactive (Eysenbach and Diepgen, 2001). Non-interactive sources of health information that include traditional media such as leaflets, books, audiotapes, videotapes, radio and TV, have been criticised as too general to meet the needs of specific users (Wallace, 1997), and therefore interactive health information resources such as interactive videodisks, CD-ROMs, health kiosks and websites have become increasingly popular (Eysenbach and Diepgen, 2001; Eysenbach and Kohler, 2002).

Potential benefits to patients of increased access to health information include supplementing information from a doctor, becoming more involved in health care decisions and improved understanding of their condition, and all these can affect patients' health care decisions, health status and mental health (Shuyler and Knight, 2003). Well-informed patients may have better health outcomes, make less use of health services and develop better relationships with their doctor (Murray et al., 2003).

Access to health information is particularly important in Glasgow and the West of Scotland as this region has some of the worst health statistics in Europe. In 2001, 18\% of deaths among under 75's in Glasgow were a result of coronary heart disease; a further $32 \%$ of deaths among Glaswegians under the age of 75 were caused by cancer (Greenwood and Tulloch, 2004). However, recognizing the importance of providing appropriate health information to the citizens, several measures have been taken in the recent past in Glasgow, and Scotland in general, to provide online health information. One of the most prominent developments is the creation of the Glasgow's Health Hub website (http://www.ghi.org.uk/glasgowshealthhub/index.asp) by the Greater Glasgow NHS Board, which provides access to quality information on health and social care. Other prominent online health information resources include the Sandyford Initiative website of sexual and reproductive health (http://www.sandyford.org/), and the Glasgow Healthy City partnership (http://www.glasgowcitycouncil.co.uk/healthycities/).

Given these initiatives, it is important to know how people in Scotland seek and use online health information. With this broad objective, a research was undertaken in summer 2004 to study how Scottish people seek and use health information, and more specifically:

- What sources people use to get health information;

- Whether and how people use the Internet to get access to health information, and

- What is the usual outcome of online health information.

This research was mainly based on a survey, as detailed in the methods section. The study also intended to assess how people use the Internet in general, and what proportion of their Internet time is spent on looking for health information, and so on.

\section{Use of the Internet for health information}

Health information has remained a major area of research all over the world for the past few years, and in the UK the CIBER research group (http://ciber.soi.city.ac.uk/ciber.php) has remained very active in researching online health information behaviour of the British, mainly English, population. However, most of the CIBER surveys use online questionnaires often placed on health websites or drawn from broadsheet newspaper membership databases resulting in sample bias, since the use of online questionnaires can target only those users who have Internet access, and hence the findings may exaggerate the use of the Internet for health information. Nevertheless, these research studies provide useful data about online health information seekers. 
Table 1: Main findings of some online health information studies

\begin{tabular}{|c|c|c|}
\hline Study & Method & Some significant findings \\
\hline $\begin{array}{l}\text { CIBER study1: } \\
\text { Nicholas et al } \\
(2003 b)\end{array}$ & Online survey & $\begin{array}{l}\text { - } 66 \% \text { of the respondents accessed the Internet from } \\
\text { home or work } \\
\text { - } 85 \% \text { had accessed the Internet in the last six } \\
\text { months, } 50 \% \text { in the last month and } 18 \% \text { in the last } \\
\text { week } \\
\text { - over } 80 \% \text { of the respondents stated that they had } \\
\text { used the Internet for health information }\end{array}$ \\
\hline $\begin{array}{l}\text { CIBER study2: } \\
\text { Nicholas et al, } \\
\text { (2001) }\end{array}$ & Online survey & $\begin{array}{l}\text { - } 80 \% \text { of health information seekers were female } \\
\text { most online health information seekers were aged } \\
35-54 \text { with very few respondents over } 75 \\
\text { - } 94 \% \text { of the respondents had no medical } \\
\text { background }\end{array}$ \\
\hline $\begin{array}{l}\text { CIBER study3: } \\
\text { Huntington et } \\
\text { al. }(2003)\end{array}$ & Onlir & $\begin{array}{l}\text { - Main reasons for searching online health } \\
\text { information are: 'alternative remedy', 'staying fit } \\
\text { and healthy' or 'keeping up to date' } \\
\text { - Use of health websites is influenced by users' age: } \\
\text { Netdoctor (http://www.netdoctor.co.uk) users } \\
\text { tended to be younger than SurgeryDoor } \\
\text { (http://www.surgerydoor.co.uk) users, and NHS } \\
\text { Direct Online users came from a higher income } \\
\text { bracket }\end{array}$ \\
\hline $\begin{array}{l}\text { CIBER study4: } \\
\text { Huntington et } \\
\text { al., (2004) }\end{array}$ & Online survey & $\begin{array}{l}\text { age, occupation, health status and the type of } \\
\text { information sought affected interest in online services } \\
\text { such as support groups and contacting online doctors }\end{array}$ \\
\hline $\begin{array}{lr}\text { Pew } & \text { Survey } \\
\text { (Fox } & \text { and } \\
\text { Fallows, } & 2003 \text { ) }\end{array}$ & $\begin{array}{l}\text { Online survey } \\
\text { in the US }\end{array}$ & $\begin{array}{l}80 \% \text { of the Internet users had used the Internet for } \\
\text { health information }\end{array}$ \\
\hline $\begin{array}{l}\text { Health on the } \\
\text { Net Foundation } \\
\text { (HONF) survey } \\
\text { (Boyer et al., } \\
\text { 2002). }\end{array}$ & $\begin{array}{l}\text { Online survey } \\
\text { among } \\
\text { European } \\
\text { population }\end{array}$ & $\begin{array}{l}\text { - Approximately } 80 \% \text { of the respondents reported } \\
\text { accessing the Internet daily from work or home } \\
\text { - } 59 \% \text { respondents sought health information for } \\
\text { themselves, } 35 \% \text { for family and } 18 \% \text { for children }\end{array}$ \\
\hline $\begin{array}{lll}\begin{array}{l}\text { Dolan } \\
(2004)\end{array} & \text { et } & \text { al } \\
\end{array}$ & $\begin{array}{l}\text { Offline } \\
\text { survey at } 2 \\
\text { GP surgeries } \\
\text { in Wales }\end{array}$ & $\begin{array}{l}\text { - } 50 \% \text { of the participants had Internet access } \\
\text { - } 50 \% \text { users had used the Internet for health } \\
\text { information }\end{array}$ \\
\hline $\begin{array}{l}\text { Study in } \\
\text { Singapore (Siow } \\
\text { et al., 2003). }\end{array}$ & $\begin{array}{l}\text { Structured } \\
\text { interview }\end{array}$ & $\begin{array}{l}\text { - } 62.9 \% \text { of the respondents used the Internet and } \\
23.7 \% \text { of Internet users had sought health } \\
\text { information online }\end{array}$ \\
\hline Diaz et al (2002) & $\begin{array}{l}\text { Offline } \\
\text { survey using } \\
\text { GP billing } \\
\text { files in the } \\
\text { Rhodes } \\
\text { Island, USA } \\
\end{array}$ & $\begin{array}{l}\text { - } 53 \% \text { of the patients used the Internet for health } \\
\text { information } \\
\text { - } 19 \% \text { of health information seekers used the } \\
\text { Internet at least once a week and } 35 \% \text { at least } \\
\text { once a month }\end{array}$ \\
\hline $\begin{array}{lll}\begin{array}{l}\text { Baker } \\
(2003)\end{array} & \text { et } & \text { al } \\
\end{array}$ & $\begin{array}{l}\text { Offline } \\
\text { survey of } \\
\text { American } \\
\text { households }\end{array}$ & $\begin{array}{l}\text { - approximately } 50 \% \text { of the sample had used the } \\
\text { Internet } \\
\text { - } 40 \% \text { of Internet users had sought health } \\
\text { information }\end{array}$ \\
\hline
\end{tabular}


Both the Pew survey in the US and the CIBER surveys in the UK used online survey techniques, and as noted in Table 1, and show a high percentage of the population using the Internet for health information. The HONF survey results are similar to the CIBER results with regard to the reasons for seeking online health information. Some findings of offline studies agree with those of online surveys. For example, Dolan et al. (2004) agreed with the online studies - both CIBER in the UK and Pew in the US - that women seek health information more often than men, and younger people (24-44) seek health information online significantly more than people aged 55 and over. Other offline surveys such as Rokade et al. (2002) and Baker et al (2003) agree with Dolan et al. (2004) on levels of Internet use for health information. The finding of Baker et al (2003) that health status influenced the use of the Internet for health confirming findings from the CIBER studies. One finding of the study in Singapore that majority of the participants seeking online health information were young with higher income and education levels corroborate the similar finding of the US and UK studies. However, levels of use for health information reported in Singapore were noted to be significantly lower than UK and US surveys despite a higher level of Internet access.

However, the offline surveys show different results in some cases. For example, (1) according to the study of Dolan et al (2004), significantly lower number of people, compared to the CIBER studies, used the Internet for health information; (2) in contrast to Dolan et al. (2004) the 2002 Pew survey indicates that more US users aged 50-64 use the Internet for health information compared to younger age groups; and (3) in contrast to Pew surveys Baker et al. (2003) found that older people were much less likely to use the Internet for health information.

\section{Methods}

It was decided to sample two separate sub-populations in Scotland to investigate the differences, if any, in Internet access, general health information seeking patterns, and use of the Internet for health and the outcome of online access to health information. The survey among the general population sample was conducted in public libraries to encompass a broad cross-section of the Scottish population including different age groups, genders and socioeconomic background. The survey was conducted offline to allow participation of individuals who are not ICT literate as this is a sub-section of the population excluded by many previous surveys conducted on-line which by definition only samples Internet users.

The second survey was conducted among students of the postgraduate Information and Library Studies (ILS) and Information Management (IM) courses at a university in Glasgow. Due to the nature of the courses this group is expected to be ICT literate as well as proficient in the use of the Internet for access to information. With this population the survey was conducted online.

The initial survey in six public libraries in Glasgow was carried in July 2004. Libraries were visited at different times of the day - morning, afternoon and evening - to increase the crosssection of the population encountered. Public libraries included in the survey were selected to cover a broad geographic area with a range of socio-economic backgrounds. In each library a poster requesting volunteers was displayed to attract participants. Approximately ten people from each library (coming from approximately one in three or four users visiting the library at the time of the survey) voluntarily completed the questionnaire; in total 64 people completed the questionnaire.

For the student survey an e-mail explaining the purpose of the survey and where to access the questionnaire was sent to all the students on the ILS and IM courses. The student on-line survey was made available in July 2004. Out of a total population of 80 in the two PG 
courses, 24 students responded to the online questionnaire. Completion of the questionnaire in both the surveys were voluntary as well as anonymous. The questionnaire consisted of mainly closed questions with a few open questions used to prompt participants to expand on answers or to elicit opinions on particular points. Sections of the questionnaire covered demographic information, Internet access, use of the Internet for health information, health information needs and the outcome of online health information search.

\section{Findings}

The two population used in this survey are different in the sense that one is a subsection of the general public that comprises users of all age, educational background and ICT and Internet capabilities. In other words, these users are not necessarily Internet savvy (though a few could be, but that would be purely an accidental selection). On the other hand, the university student population chosen for this study had already completed the taught elements of a postgraduate ILS or IM course, and therefore were expected to be proficient in the use of ICT and the Internet. Thus we had two user populations - a general population of 64 respondents, and a proficient Internet user group comprising 24 people.

\section{General demographics}

A total of 24 university students (proficient Internet users) and 64 members of the general public participated in the survey. The general characteristics of the user population are shown in Table 1.

Table 1: General characteristics of the user population - age and occupation

\begin{tabular}{|c|c|c|}
\hline Criteria & General public (\%) & University Students (\%) \\
\hline \multicolumn{3}{|l|}{ Age groups } \\
\hline Under 25 & 22 & 23 \\
\hline $25-34$ & 17 & 63 \\
\hline $35-44$ & 16 & 14 \\
\hline $45-54$ & 16 & - \\
\hline $55-64$ & 13 & - \\
\hline Over 65 & 13 & - \\
\hline No response & 3 & - \\
\hline \multicolumn{3}{|l|}{ Occupation } \\
\hline Full-time employment & 33 & 29 \\
\hline Part-time employment & - & 21 \\
\hline Full-time student & 19 & 50 \\
\hline Unemployed & 22 & - \\
\hline Retired & 19 & - \\
\hline Self employed & 2 & - \\
\hline No response & 5 & - \\
\hline
\end{tabular}

In the general user population, $56 \%$ were women and $44 \%$ men; $36 \%$ were single, $40 \%$ were married, $13 \%$ lived with a partner and $11 \%$ were separated, divorced or widowed; the sample was almost exclusively white in ethnic origin (91\%), partly due to a low encounter rate of ethnic minorities in the public libraries chosen for data collection. Among the student user group, $87.5 \%$ were women; $84 \%$ of the respondents were single, $8 \%$ were married and $8 \%$ lived with a partner; $88 \%$ were white in ethnic origin (88\%), $4 \%$ were Chinese, and $8 \%$ were unknown (people who did not choose to respond to this question).

\section{Internet access}

Half of the general user population (50\%) reported that they had used the Internet before, and of these $41 \%$ felt that they were confident Internet users. Respondents who had not used the 
Internet were all over 45. From among the Internet users in the general user population, 27\% reported to have used the Internet daily, and the equal number used the Internet 2-3 times per week; $11 \%$ used the Internet once a week, $5 \%$ used $2-3$ times a month, $2 \%$ used once a month, and $8 \%$ used it occasionally.

All the university students, by virtue of their training, were proficient Internet users. All the students used the Internet at least 2-3 times a week, with $88 \%$ reported to have used it daily. The average search session for most of the students (58\%) lasted over 15 minutes, and only $13 \%$ spent less than 5 minutes per search session. Table 2 shows the common places of access to the Internet for both the user groups.

Table 2: Place of access to the Internet

\begin{tabular}{|l|l|l|}
\hline Internet access & General public (\%) & University students (\%) \\
\hline Home & 27 & 47 \\
\hline Work & 16 & 18 \\
\hline School/University & 9 & 23 \\
\hline Public library & 42 & 10 \\
\hline other & 6 & 2 \\
\hline
\end{tabular}

\section{Use of the Internet for Health Information}

Just over a third of the general user population (37\%) as opposed to $71 \%$ of the student population had used the Internet for health information. There was no gender effect on the use of the Internet for health information. Almost all the general user participants who had sought health information online reported that they found information easily or very easily, only $2 \%$ reported that health information was difficult to find. Surprisingly, only $41 \%$ of the students (i.e. proficient Internet users) seeking health information online reported to have found the information easily, and 30\% felt health information was either difficult or very difficult to find. For both the groups of user population, the most common means for finding health sites were by searching or browsing: for the general population the choices were browsing (33\%) followed by the use of a search engine $(21 \%)$, while for the student population it was searching (40\%) followed by browsing (29\%).

It was noted that women were more likely to find health websites by browsing $(43 \%)$, following links $(21 \%)$, or searching $(20 \%)$. Men found health websites using search engines (26\%), browsing (25\%), through links (165) or adverts (13\%). Majority of the general public used 2-5 websites when seeking health information, and $91 \%$ of the online health information seekers reported satisfaction with the information they found. Approximately two-thirds $(67 \%)$ of the respondents seeking health information online checked the source of information they found. All the student respondents used 2-3 websites to find sufficient health information, and most of the students checked the source of the information, and almost all were satisfied with the information found.

\section{Online health information needs and outcome}

All the survey participants used a range of sources to find health information, the most commonly used one being the GP or health centre $-34 \%$ for the general public and $27 \%$ for the student population. Only $18 \%$ of the general population, and $26 \%$ of the students used the Internet as a source of health information; and almost an equal percentage of both the population have noted to consult family and friends for health information. Little difference was detected in the sources of health information used by Internet users and those who do not use the Internet. Surprisingly Internet users use the GP more than non-Internet users suggesting a greater general interest in health. Those who do not use the Internet showed more interest in using the public library for health information. Sources of health information 
used by members of the general public are also influenced by gender. Men were more likely to use the Internet $(21 \%)$ for health information. Women used family or friends $(20 \%)$, the public library (11\%) and the chemist (18\%) more frequently than men to find health information. Both men and women used the GP almost equally (34\% and 35\% respectively). Respondents from the general public preferred health information in books or leaflets; as a second preference most participants cited leaflets; and articles in a magazine or a website were the third preference for most participants. For the student population, websites were the most preferred choice, with leaflets and magazine articles or books being the second and third preferences.

\section{Purpose for seeking online health information}

Nearly half $(46 \%)$ of the general participants sought online health information for themselves, $27 \%$ for relatives, $12 \%$ for children, $9 \%$ for friends and $4 \%$ for colleagues. Women were slightly more likely to seek health information for relatives and children, while men were slightly more likely to look for health information for themselves or for colleagues. Respondents cited a range of purposes for seeking health information (Figures 1 and 2). For the general population, the most common reasons for seeking health information were healthy living (20\%), general interest (17\%) and finding out about a diagnosed condition (17\%). For the student population the most common reasons for seeking health information were to find out about a diagnosed condition (20\%), healthy living (18\%), prepare for a visit to the doctor $(15 \%)$ and general interest $(14 \%)$.

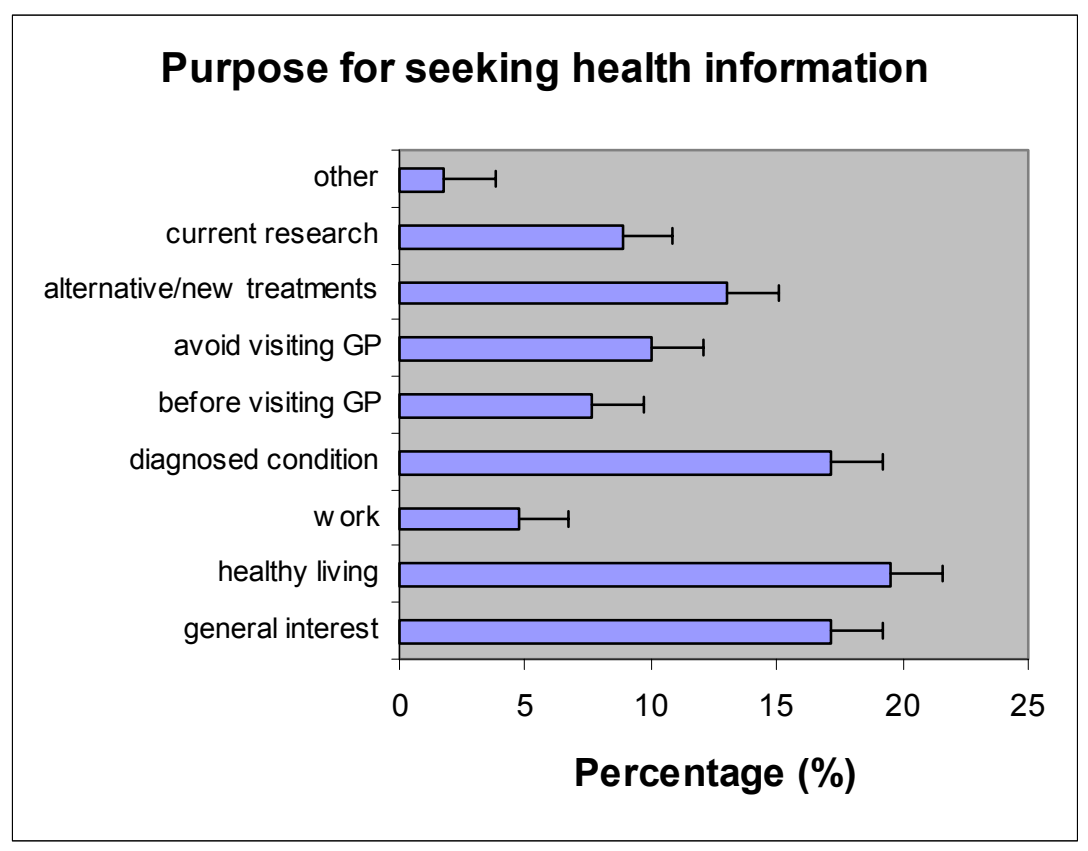

Figure 1: Purpose for seeking health information (general public)

Users were given a list of topics to choose from and rank them as the topics commonly looked for in the health information sites. As shown in Figure 3, the most commonly cited topics of interest by the general user population were healthy eating (14\%), exercise $(11 \%)$ and alternative medicine (9\%). A small number of participants were not interested in any health topic. Among the students the most frequently sought health topics were healthy eating $(15 \%)$, exercise (13\%) and treatments (12\%) (Figure 4). 


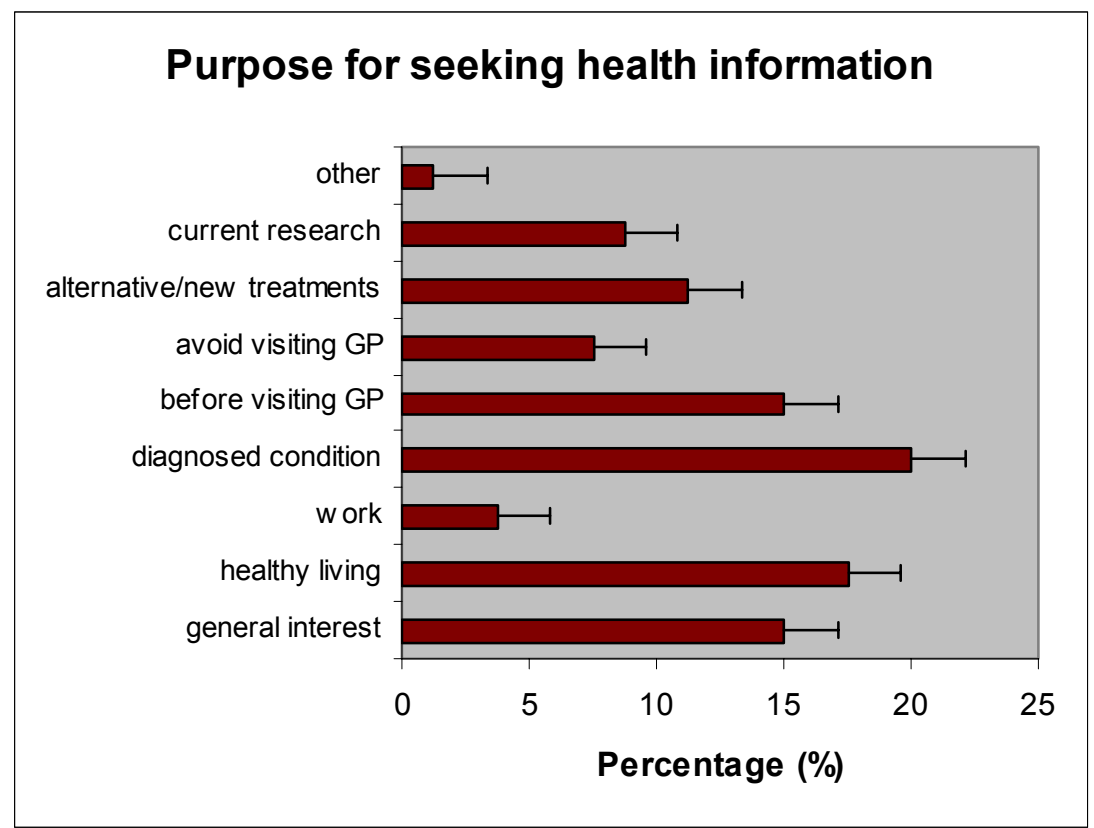

Figure 2: Purpose for seeking health information (students)

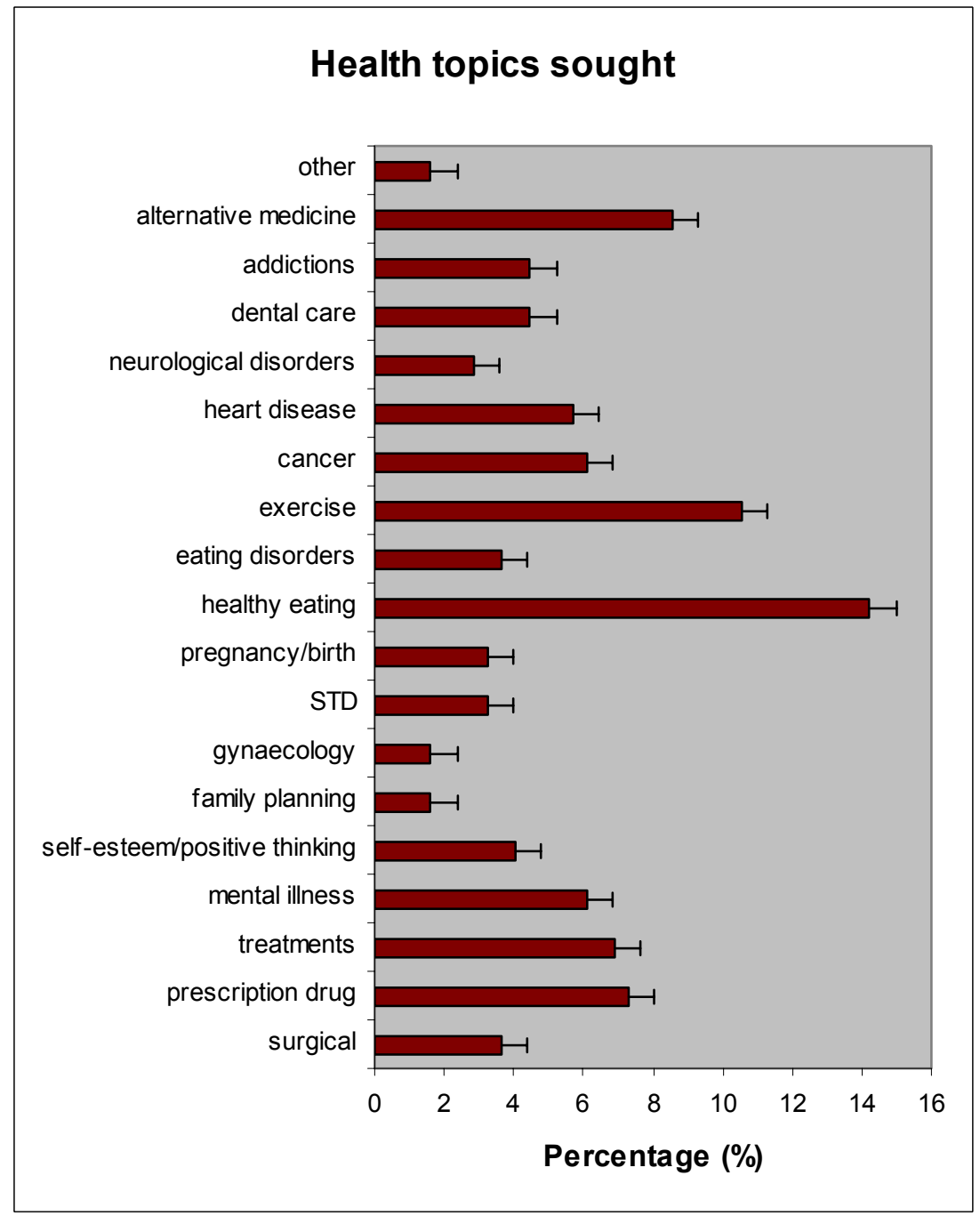

Figure 3: Health topics of interest (general public) 
A comparison of the topics of interest to men and women in the general user population indicated differences in health priorities (5). The topic for the first choice for online health information for both men and women was healthy eating (15\% for both the gender). However, the second and third choices were different: women showed more interest in alternative medicine $(11 \%)$ and exercise $(9 \%)$, while men showed interests in exercise (13\%) and heart disease $(10 \%)$.

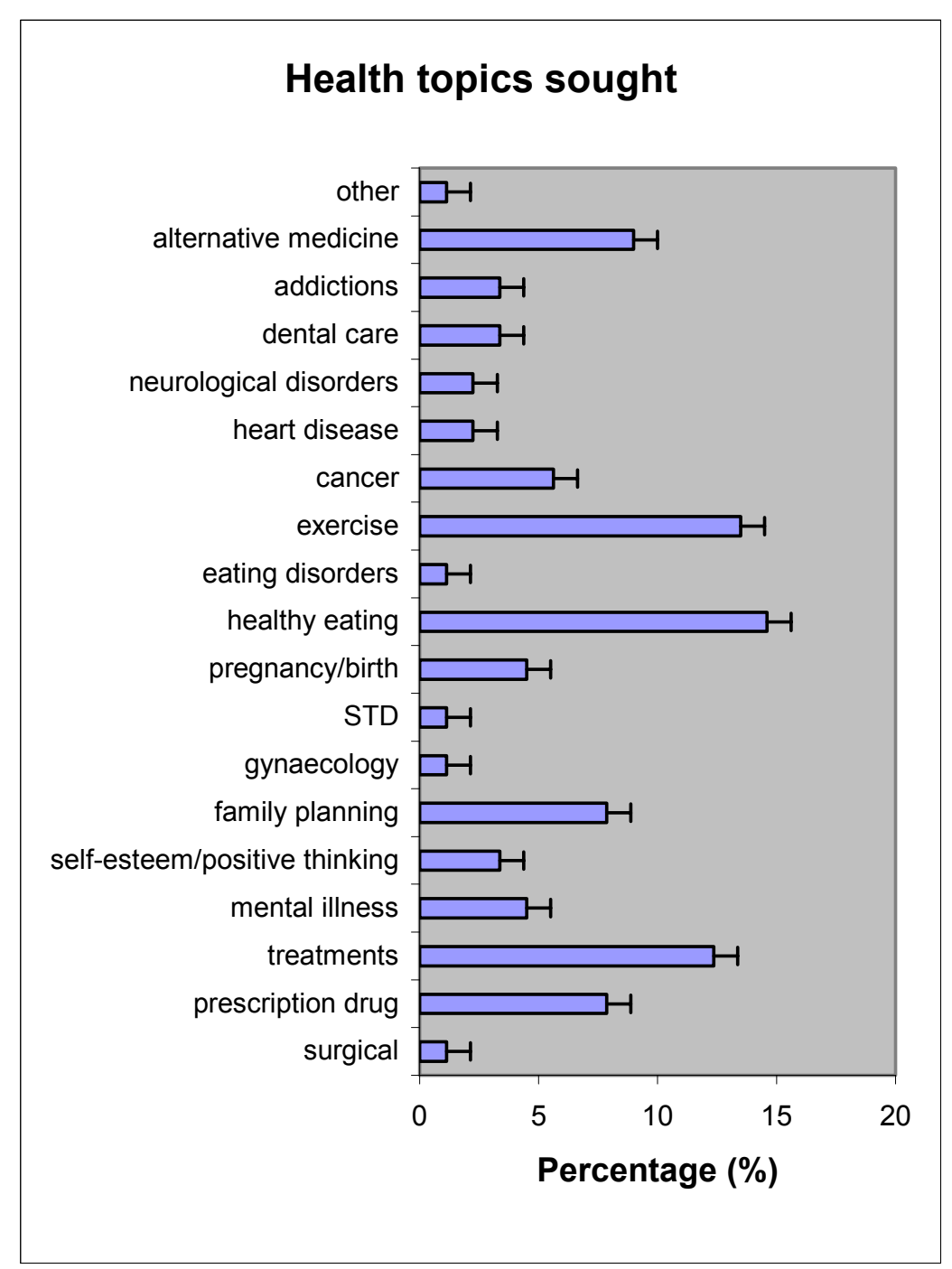

Figure 4: Health topics sought by students

\section{Outcomes of online health information access}

As many as $61 \%$ of online health information seekers from the general public had taken action as a result of information found on the Internet. The most common actions taken as a result of online health information were visiting a GP or changing diet. It may be noted that a significant proportion of the users failed to specify the actions taken as a result of an online health search. 


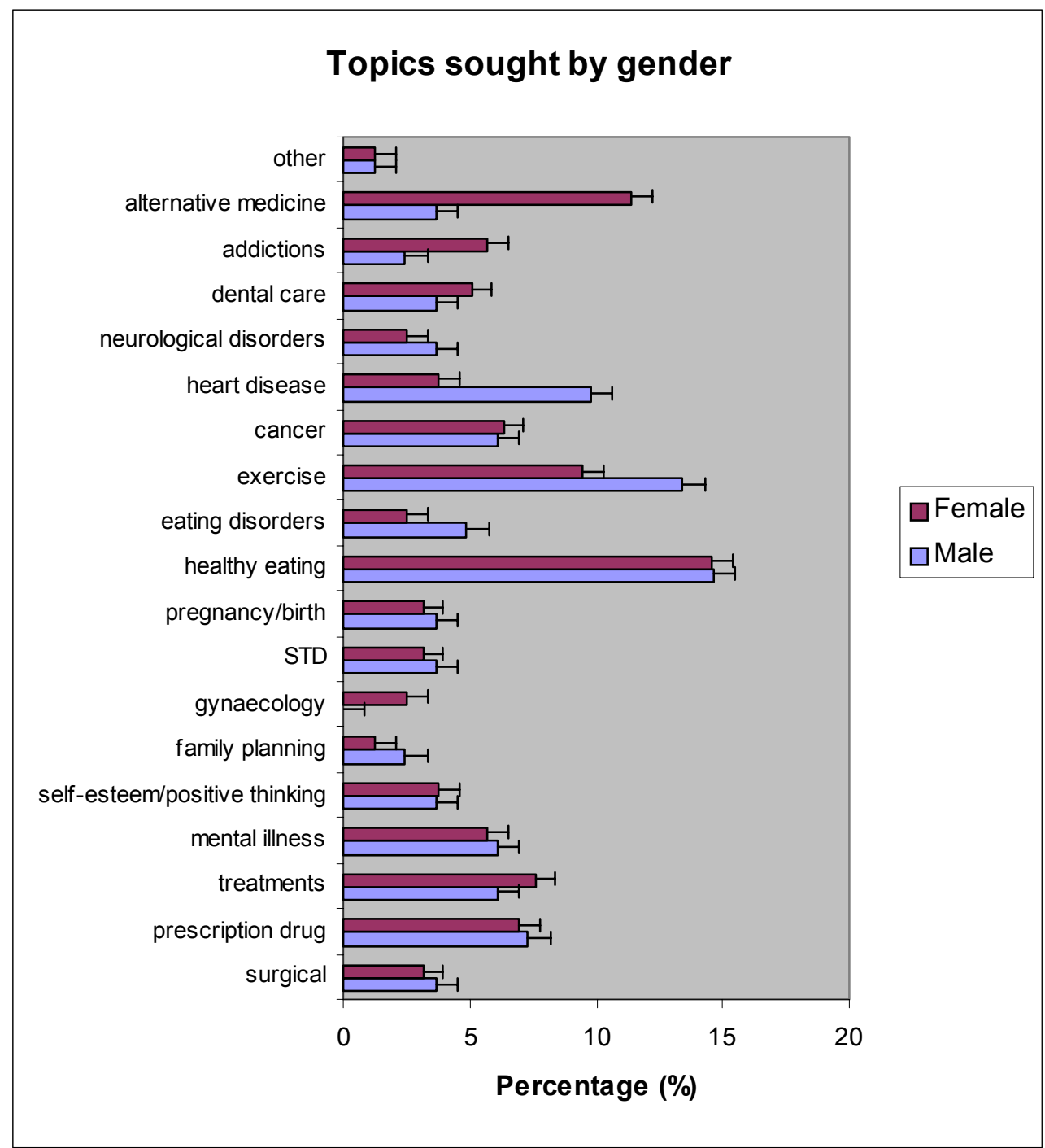

Figure 5: Gender differences in health topics sought

About half of the online health information seekers felt that information found on the Internet had influenced their treatment. However, in all cases respondents felt information found online had no effect on the doctor-patient relationship. The most frequently cited benefits of online health information were noted to be increasing understanding, prompting action, providing reassurance, and encouraging self-help.

\section{Summary and Discussions}

The findings of this research are discussed below and compared with the findings of related research in UK and elsewhere.

\section{Internet access}

This survey shows that $50 \%$ of the general public had used the Internet, a finding that agrees to the previous offline surveys in the UK (Dolan et al., 2004) and the US (Baker et al., 2003). The finding that all the Internet users in the general user group were under 45 corroborates the previous findings that Internet users were young (Nicholas et al., 2003b; Dolan et al., 2004) and that a 'grey gap' in Internet access exists (Benigeri and Pluye, 2003). Internet use among student respondents was significantly higher with $100 \%$ of participants using the Internet. This is not unexpected as this group covers a younger age group with a stronger ICT background. 
Only about $37 \%$ of the general public had used the Internet for health. While this finding is consistent with an offline survey in the US (Baker et al 2003) that reported $40 \%$ users sought online health information, it is in sharp contrast with the online surveys by Nicholas et al. (2003b) in the UK and Fox and Fallows (2003) in the US found that $80 \%$ of Internet users sought health information. These differences in results may arise from sampling issues as the highest figures come from online surveys followed by surveys conducted in GP surgeries and finally surveys of the general population, in this case public library customers. Students had used the Internet for health information more than the general public (71\%) lending credence to the theory that online surveys sample a specific Internet competent subset of the population (Gunter et al., 2002).

Interestingly the student population reported more difficulties in finding online health information than the general public. This finding could be the result of more specific queries by students or less willingness to accept information without ascertaining quality and usability. In both surveys finding health information using search engines or browsing was common. While results from a previous survey by the CIBER research group concur that search engines are the most frequently used method of finding health information (Nicholas et al., 2001) the actual proportions differ and the studies disagree on the second most common method with CIBER suggesting users read about websites while the current study found browsing was more frequently used.

The current survey shows that men and women find health websites differently, a conclusion supported by a CIBER survey (Nicholas et al., 2001). The majority of health information seekers in both samples used 2-5 health websites to find information suggesting that Internet users are not content to accept advice from a single source and may validate information by checking other online resources. This finding is agrees with the CIBER group study(Nicholas et al., 2003b).

Encouragingly two thirds of the respondents checked the provider of health resources they used, and this figure is higher than the $50 \%$ reported by Nicholas et al. (2003b) and suggest a growing awareness that quality of online material is variable and needs to be checked before accepting advice. Satisfaction levels of participants in the current study with health information found were higher (91\%) than in previous research where $71 \%$ of respondents were satisfied with the information found (Rokade et al., 2002).

\section{Health information needs and outcomes of online access}

Among members of both the users groups, GP was the most commonly used source of health information, a finding that is consistent with the previous studies (Nicholas et al., 2001; Dolan et al., 2004; Diaz et al., 2002; Cotten and Gupta, 2004). The continued reliance of even the Internet proficient user group on the GP would seem to suggest that having access to online health information is not sufficient to reduce pressure on the conventional health services.

Contrary to the previous findings that women use the Internet more for health information (Fox and Fallows, 2003; Dolan et al., 2004; Nicholas et al., 2001) the current survey shows that men in Scotland make more frequent use of the Internet for health. The finding that the general public preferred information in traditional formats such as leaflets and books, whereas the Internet proficient user group preferred online health information suggests that the traditional sources will continue to play an important role in health information dissemination. In terms of distributing health information to the public in Scotland this is an important consideration as the longer lifespan of people today means a generation preferring traditional formats for health information will persist and will need to be catered for both now and in the 
future. The situation may change as and when the general population become more frequent Internet users and gain proficiency in Internet searching.

In the earlier surveys in UK respondents have been reported to seek information for themselves, relatives and children (Nicholas et al., 2003b), as is the case in the current survey. In the current study respondents sought health information for a range of reasons, the most common one being to find out about a diagnosed condition and healthy living, and this is in agreement with the CIBER study (Nicholas et al., 2003b). The top three health topics sought through online health information services were similar for both the user groups with healthy eating and exercise as the top two and either alternative medicine or treatments as the third option; this is in contrast with the CIBER study that found higher levels of interests in alternative medicine (Nicholas et al., 2003b) or high levels of interest in general health and diet (Huntington et al., 2003).

Among the general population there was a gender difference in health topics of interest with men showing more interest in exercise and heart disease and women expressing interest in alternative medicine and treatments. An interest among men in the West of Scotland in heart disease is a welcome result as heart disease statistics around Glasgow are very high (Greenwood and Tulloch, 2004). All of the topics participants expressed an interest in could be considered as the important current health issues. Examples of such topics include: heart disease, healthy living, alternative therapies, and awareness campaigns.

Participants in both samples who had used online health services used the Internet primarily to search or diagnose a condition. Nobody in the current study had contacted a GP online suggesting a lack of trust in online doctors and an inability to e-mail their own GP. The lack of interest in online support groups by survey participants suggests these do not play an important role in communicating health information at present. These results contradict a recent survey by Nicholas et al. (2003b) where 14\% of participants used support groups and $18 \%$ e-mailed a doctor or sought advice from an online doctor. Capacity for filling prescriptions through the Internet is also limited as only $9 \%$ bought medicine online compared to $15 \%$ in CIBER studies (Nicholas et al., 2003b). This lack of interest in online purchasing of medication could be considered a good thing as online availability of medicines raises ethical issues as people may have access to medication that is inappropriate and potentially harmful. The HONF survey in 2002 (Boyer et al., 2002) found that most people sought health information or purchased medication online and $23 \%$ e-mailed a doctor. Differences in results between these studies may be due to the methodology used as Nicholas et al. (2003b) and Boyer et al. (2002) used online surveys thereby polling a group comfortable using the Internet. Other offline survey results more closely reflect current findings with $54 \%$ of users searching for information and $5 \%$ purchasing medicines online (Baker et al., 2003).

In cases where action was taken as a result of online health information visiting a doctor was the most common response. This suggests that people are willing to act upon information found online but the action taken is to visit a GP. As with health topics and search purposes a range of benefits were of interest to survey participants with reassurance and increased understanding being the most common; this finding is consistent with previous studies (Baker et al., 2002 and Nicholas et al., 2003b.

\section{Conclusions}

Given the small size of the study population it may not be wise to generalise some of the findings, but this study provides a snapshot of the current state of online health information use in Scotland. It is quite encouraging to note that more people in Scotland now access the Internet, and among those who do so use the Internet daily or at least 2-3 times a week. However, it is noted that the general population in Scotland use the internet for online health 
information much less frequently compared to those in England and elsewhere, as reported in the earlier studies. Nevertheless, over two-thirds the Internet savvy user group use the Internet for online health information, and majority prefer health information in the online format compared to the traditional print formats. It may therefore be concluded that as people become more proficient in the use of the Internet, their use of online health information will increase.

It is noted that despite having access to online health information, people generally prefer to consult their GPs to discuss their health issues. While this may mean that the creation of online health information services do not reduce the load on the NHS, it has been noted that access to online health information increases awareness and provides reassurance. Thus increased access to online health information will increase general awareness of healthy lifestyle, and will enable people to take some simple precautionary and preventive measures, and to be more informed about the public health issues. For example, this research shows that the Scottish population use the online services for information on healthy lifestyle, heart diseases, exercises and healthy eating. This is especially encouraging for Glasgow and Scotland, and appropriate campaigns should be initiated to encourage more use of online health information as a mechanism for increasing the general awareness and preventive measures. This will in turn help us create a healthy Scotland.

Finally, while it is encouraging to note that members of the general public have also been using online health information, it should be noted that use of online health information, and Internet access in general, is influenced by a number of technical, educational and socioeconomic factors. Access to Internet, and consequently to online health information, may yet not be very common for the most vulnerable sections of the society comprising the poor, the unemployed, old age pensioners, less educated and socially disadvantaged people, sick and disabled people, and so on, who need health information more frequently.

In order to help people and the society maintain good health, it is important to facilitate access to online health information, and as a first step to this, it is important to undertake a large survey involving general users from all sections of the society in order to get a true picture of the use of online health information, and more importantly to identify the barriers to online information access and use in Scotland. Government, local authorities, health bodies and professional associations, and information scientists should work together to build a well informed and healthy Scotland.

\section{References}

Baker, L., Wagner, T.H., Singer, S. and Bundorf, M.K. (2003), "Use of the Internet and email for health care information: results from a national survey", Journal of the American Medical Association, Vol 289 No 18, pp. 2400-2406.

Benigeri, M. and Pluye, P. (2003) "Shortcomings of health information on the Internet", Health Promotion International, Vol 18 No 4, pp.381-386.

Boyer, C., Provost, M. and Baujard, V. (2002), “Excerpt of the $8^{\text {th }}$ HON's survey of health and medical Internet users", Health on the Net Foundation. Available at http://www.hon.ch/Survey/8th_HON_results.html. (Accessed 15 June 2004)

Cline, R.J.W. and Haynes, K.M. (2001), "Consumer health information seeking on the Internet: the state of the art", Health Education Research, Vol 16 No 6, pp. 671-692. 
Cotten, S.R. and Gupta, S.S. (2004), "Characteristics of online and offline health information seekers and factors that discriminate between them" Social Science and Medicine, Vol 59 No 9, pp. 1795-1806.

Diaz, J.A., Griffith, R.A., Ng, J.J., Reinert, S.E., Friedmann, P.D. and Moulton, A.W. (2002), "Patients' use of the Internet for medical information" Journal of General Internal Medicine, Vol 17, pp. 180-185.

Dolan, G., Iredale, R., Williams, R. and Ameen, J. (2004), "Consumer use of the Internet for health information: a survey of primary care patients" International Journal of Consumer Studies, Vol 28 No 2, pp.147-153.

Eysenbach, G. and Diepgen, T.L. (2001), "The role of e-health and consumer health informatics for evidence-based patient choice in the $21^{\text {st }}$ century" Clinics in Dermatology, Vol 19, pp. 11-17.

Eysenbach, G. and Kohler, C. (2002), "How do consumers search for and appraise health information on the World Wide Web? Qualitative study using focus groups, usability tests and in-depth interviews" British Medical Journal, Vol 324, pp. 573-577.

Fox, S. and Fallows, D. (2003), "Internet health resources: health searches and e-mail have become more commonplace, but there is room for improvement in searches and overall Internet access" PEW Internet and American Life Project. Available at: http://www.pewinternet.org. (Accessed 15 June 2004)

Fox, S. and Rainie, L. (2002), "Vital decisions: how Internet users decide what information to trust when they or their loved ones are sick", PEW Internet and American Life Project. Available URL: http://www.pewinternet.org. Cited 15 June 2004.

Garnes, D. and Mills, C. (2001), "Finding and evaluating health sources on the Internet: an overview" Reference Librarian, Vol 74, pp. 177-186.

Greenwood, N. and Tulloch, P. (2004), "Working for a healthy city", Information Scotland, Vol. 2 No 3, pp. 14-15.

Huntington, P., Nicholas, D. and Williams, P. (2003), "Characterising and profiling health web user and site types: going beyond "hits" ", Aslib Proceedings, Vol.55 No 5/6, pp.277289.

Huntington, P., Nicholas, D., Homewood, J. and Polydoratou, P., (2004), The general public's use of (and attitudes towards) interactive, personal digital health information and advisory services, Journal of Documentation, Vol 60 No 3, pp. 245-265.

Murray, E., Lo, B., Pollack, L., Donelan, K., Catania, J., Lee, K., Zapert, K. and Turner, R. (2003), "The impact of health information on the Internet on health care and the physicianpatient relationship: national U.S. survey among 1,050 U.S. physicians", Journal of Medical Internet Research, Vol 5 No 3 Available at http://www.jmir.org/2003/3/e17. (Accessed 10 June 2004)

Nicholas, D., Huntington, P., Williams, P. and Blackburn, P. (2001), "Digital health information provision and health outcomes" Journal of Information Science, Vol 27 No 4, pp. 265-276. 
Nicholas, D., Huntington, P. and Williams, P. (2003a). Delivering consumer health information digitally: a comparison between the web and touchscreen kiosk. Journal of Medical Systems. 27 (1), p13-34.

Nicholas, D., Huntington, P., Gunter, B., Russell, C. and Withey, R. (2003b). The British and their use of the Web for health information and advice: a survey. Aslib Proceedings. 55 (5/6), p261-276.

Rokade, A., Kapoor, P.K.D., Rao, S., Rokade, V., Reddy, K.T.V. and Kumar, B.N. (2002). Has the Internet overtaken other traditional sources of health information? Questionnaire survey of patients attending ENT outpatient clinics. Clinical Otolaryngology. 27, p526-528.

Shuyler, K.S. and Knight, K.M. (2003). What are patients seeking when they turn to the Internet? Qualitative content analysis of questions asked by visitors to an orthopaedics web site. Journal of Medical Internet Research. 5 (4), e24. Available URL: http://www.jmir.org/2003/5/e24/index.htm. Cited 24 June 2004.

Siow, T.R., Soh, I.P.T., Sreedharan, S., Das De, S., Tan, P.P., Seow, A. and Lun, K.C. (2003). The Internet as a source of health information among Singaporeans: prevalence, patterns of health surfing and impact on health behaviour. Annals of the Academy of Medicine Singapore. 32 (6), p807-813.

Wallace, S. (1997). Health information in the new millennium and beyond: the role of computers and the Internet. Health Education. 3, p88-95.

Williams, P., Nicholas, D., Huntington, P. and Gunter, B. (2002a). Doc.com: reviewing the literature on remote health information provision. Aslib Proceedings. 54 (2), p127-141.

Williams, P., Huntington, P. and Nicholas, D. (2003). Health information on the Internet: a qualitative study of NHS Direct Online users. Aslib Proceedings. 55 (5/6), p304-312.

Wilson, S.M. (1999). Impact of the Internet on primary care staff in Glasgow. Journal of Medical Internet Research. 1 (2), Available URL: http://www.jmir.org/1999/2/e7/index.htm. Cited 5 July 2004. 